\title{
Integrating ecosystem services and disservices: insights from plant invasions
}

\author{
Ana S. Vaz ${ }^{\mathrm{a}, \mathrm{b}, *}$, Christoph Kueffer ${ }^{\mathrm{c}, \mathrm{d}}$, Christian A. Kull ${ }^{\mathrm{e}, \mathrm{f}}$, David M. Richardson ${ }^{\mathrm{d}}$, \\ Joana R. Vicente ${ }^{\mathrm{a}, \mathrm{g}}$, Ingolf Kühn ${ }^{\mathrm{h}, \mathrm{i}, \mathrm{j}}$, Matthias Schröter ${ }^{\mathrm{j}, \mathrm{k}}$, Jennifer Hauck ${ }^{\mathrm{l}, \mathrm{m}}$, Aletta Bonn ${ }^{\mathrm{j}, \mathrm{k}, \mathrm{n}}$, \\ João P. Honrado ${ }^{\mathrm{a}, \mathrm{b}}$
}

${ }^{a}$ Research Network in Biodiversity and Evolutionary Biology, Research Centre in Biodiversity and Genetic Resources (InBIO-CIBIO), Campus Agrário de

Vairão, Rua Padre Armando Quintas, PT4485-661 Vairão, Portugal

b Faculty of Sciences, University of Porto, Rua do Campo Alegre, s/n, PT4169-007 Porto, Portugal

${ }^{\mathrm{c}}$ Institute of Integrative Biology, ETH Zurich, Universitätstrasse 16, CH-8092 Zurich, Switzerland

a Centre for Invasion Biology, Department of Botany and Zoology, Stellenbosch University, Matieland 7602, South Africa

e Institute of Geography and Sustainability, University of Lausanne, 1015 Lausanne, Switzerland

${ }^{\mathrm{f}}$ Centre for Geography and Environmental Science, Monash University, Melbourne, Vic 3800, Australia

${ }^{g}$ Laboratory of Applied Ecology, CITAB - Centre for the Research and Technology of Agro-Environment and Biological Sciences, University of Trás-osMontes e Alto Douro, Vila Real, Portugal

h Department of Community Ecology, UFZ - Helmholtz Centre for Environmental Research, Theodor-Lieser-Str. 4, 06120 Halle, Germany

i Geobotany and Botanical Garden, Martin-Luther-University Halle-Wittenberg, Am Kirchtor 1, 06108 Halle, Germany

${ }^{j}$ German Centre for Integrative Biodiversity Research (iDiv) Halle-Jena-Leipzig, Deutscher Platz 5e, 04103 Leipzig, Germany

k Department of Ecosystem Services, UFZ - Helmholtz Centre for Environmental Research, Permoserstr. 15, 04318 Leipzig, Germany

${ }^{1}$ UFZ - Helmholtz Centre for Environmental Research, Permoserstr. 15, 04318 Leipzig, Germany

m CoKnow Consulting, Mühlweg 3, 04838 Jesewitz, Germany

n Institute of Ecology, Friedrich Schiller University Jena, Dornburger Str. 159, 07743 Jena, Germany

\section{A R T I C L E I N F O}

\section{Keywords:}

Biological invasions

Ecosystem function

Human valuation

Invasive species

Social-ecological management

\begin{abstract}
A B S T R A C T
There is growing interest in ecosystem disservices, i.e. the negative effects of ecosystems on humans. The focus on disservices has been controversial because of the lack of clarity on how to disentangle ecosystem services and disservices related to human wellbeing. A perspective that considers both services and disservices is needed to inform objective decision-making. We propose a comprehensive typology of ecosystem disservices, and present a framework for integrating ecosystem services and disservices for human wellbeing linked to ecosystem functioning. Our treatment is underpinned by three key assumptions: (1) ecosystem attributes and functions are value-free; (2) the perception of benefits or nuisances are however dependent on societal context, and preferences and actions by societal actors may trigger, enhance or alleviate benefits or nuisances derived from ecosystems; and (3) the notion of disservices must account for the role of human management in assessments of ecosystem values, i.e. the social and technological measures that identify, protect, promote or restore desirable levels of services, and concurrently minimise, mitigate or adapt to disservices. We illustrate our ideas with examples from plant invasions as a complex social-ecological phenomenon.
\end{abstract}

\section{Introduction}

The concept of ecosystem services (ES) has emerged from the recognition that complex interactions in ecosystems can result in flows of energy, matter and information, which contribute to human wellbeing. Examples include fostering basic needs through food, fibre and energy provision as well as regulation services (e.g. carbon sequestration, pollination, pest control) and contributions to cultural aspects of wellbeing (Agarwala et al., 2014; Díaz et al., 2015; MA, 2005; Smith et al., 2013). The focus on ES has created an additional perspective which differs from, and is complementary to, traditional conservation policies for ensuring the sustainable use and the protection of

\footnotetext{
* Corresponding author at: Research Network in Biodiversity and Evolutionary Biology, Research Centre in Biodiversity and Genetic Resources (InBIO-CIBIO), Campus Agrário de Vairão, Rua Padre Armando Quintas, PT4485-661 Vairão, Portugal.

E-mail addresses: asofia.vaz@fc.up.pt (A.S. Vaz), christoph.kueffer@env.ethz.ch (C. Kueffer), Christian.Kull@unil.ch (C.A. Kull), rich@sun.ac.za (D.M. Richardson), jsvicente@fc.up.pt (J.R. Vicente), ingolf.kuehn@ufz.de (I. Kühn), matthias.schroeter@idiv.de (M. Schröter), jennifer.hauck@ufz.de (J. Hauck), aletta.bonn@idiv.de (A. Bonn), jhonrado@fc.up.pt (J.P. Honrado).
} 
ecosystems (Agarwala et al., 2014; Bonn et al., 2016; Brown and Westaway, 2011). Yet, one of the major recurring points of criticism of the notion of ES is that it often considers only the beneficial outputs of ecosystems and ignores unpleasant, unwanted or economically harmful effects (Lyytimäki and Sipilä, 2009; Lyytimäki, 2014; Schröter et al., 2014). These negative sides of ecosystems have been termed ecosystem disservices (EDS). Following Shackleton et al. (2016: p. 590), EDS are "the ecosystem generated functions, processes and attributes that result in perceived or actual negative impacts on human wellbeing".

EDS can be produced, for example, by biological invasions (Shackleton et al., 2016), and by other ecosystem attributes that are perceived as unwanted (Escobedo et al., 2011; Lyytimäki et al., 2008). They are produced by ecosystem functions, such as wildfires or floods, which pose danger to people and - although they may constitute natural processes - can be mitigated or exacerbated through management (Lyytimäki, 2014). The same ecosystem function may be perceived as ES by some people and EDS by other people (cf. Saunders and Luck, 2016), depending on, among other things, acquired knowledge, people's behaviours, and overall political, economic and social settings (Rasmussen et al., 2016; Shackleton et al., 2016; Stoll et al., 2015). Configuration of anthropogenic pressures as well as provision and perceptions of ES and EDS may vary spatially, temporally and between individuals or societal groups (Chan et al., 2012; Shackleton et al., 2016).

The notion of EDS has its main roots in urban ecosystem research (Dobbs et al., 2014; Escobedo et al., 2011; Lyytimäki, 2014; Lyytimäki and Sipilä, 2009), particularly in work associated with complex humanenvironment systems that characterise large cities (von Döhren and Haase, 2015). EDS have been used to evaluate the value of green space for urban residents (Lyytimäki and Sipilä, 2009; Lyytimäki et al., 2008) given that urban green spaces can provide many ES but also a range of EDS, from allergenic substances and volatile compounds emitted by vegetation (Dobbs et al., 2014), to blocking of sunlight by trees (Roy et al., 2012), and the presence of wild animals in people's backyards (Lyytimäki, 2014). The notion of EDS has also been extended to agricultural systems (e.g. Ma et al., 2015; Schäckermann et al., 2015) to account for problematic aspects of human managed ecosystems (Ma et al., 2015), to denote increases in production costs e.g. for pest control (Schäckermann et al., 2015; Swinton et al., 2007; Zhang et al., 2007), or other ecological costs arising from animal activities (Kronenberg, 2014; Whelan et al., 2015).

The usefulness of EDS has more recently been discussed for other contexts, namely fisheries and forests (see Shackleton et al., 2016). Yet, EDS have seldom been considered in the context of broader socialecological challenges (Saunders and Luck, 2016; Shackleton et al., 2016), such as plant invasions. Plant invaders provide both benefits (Tassin and Kull, 2015) and nuisances (Simberloff et al., 2013) for human wellbeing, depending on people's preferences and the spatiotemporal context (Kueffer and Kull, 2017). In some contexts, invasive plants contribute to people's livelihoods, by supporting daily basic needs and economic incomes (Kull et al., 2011), or by enhancing regulating functions, including coastal sediment dynamics and soil protection. In other contexts, however, plant invasions can lead to undesirable outcomes for human wellbeing. Examples include health problems associated with allergenic compounds or skin irritations, wildfires in non-fire prone areas, or competition with another serviceproviding species (Fenesi et al., 2015; Gaertner et al., 2014). The beneficial or detrimental impacts of plant invasions can be exacerbated by the magnitude, rate and scale of the invasion process (e.g. Eviner et al., 2012). The same species can promote ES at some spatiotemporal extent, e.g. trees confined to private gardens, or contribute to EDS provision at later stages, e.g. trees become widespread in the wild (the "transient disservices"; Saunders and Luck, 2016). This inevitably depends on (the lack of) human management (Brundu and Richardson, 2016).

Previous attempts to categorise EDS have relied on comparisons with pre-established classifications of ES. For instance, Ma et al. (2014) introduced the term 'provisioning and regulating EDS' to account for soil loss in agricultural systems. Price (2014) used 'supporting and regulating EDS' in the context of forestry. Other authors, mostly in reference to urban ecosystems (von Döhren and Haase, 2015), proposed mixed typologies, based on both the origin and consequences of EDS. Escobedo et al. (2011) classified EDS as financial (economic costs triggered by EDS), social (impacts on human health and fear) or environmental (affecting intrinsic ecosystem attributes). Lyytimäki and Sipila (2009) categorised EDS based on their origin (as social, socialecological or ecological), and based on the impacted societal actors (individuals, communities, or humankind). More recently, Lyytimäki (2014) categorised EDS with respect to weather-related events and ecosystem functions causing harm, as well as human fears and risks, activities, or aesthetic issues. Despite their usefulness in specific cases, the above-mentioned typologies do not yet provide the means for distinguishing between the occurrence of a perceived negative service, i.e. an EDS, and the reduction of an ES. For instace, a lack of an explicit differentiation of reduced ES and genuine EDS led to ambiguity in the literature (Shackleton et al., 2016), e.g. by denoting habitat loss (Zhang et al., 2007) and pesticide output in agricultural systems (Swinton et al., 2007) as EDS. To tackle the conceptual problem that reduced ES are not necessarily EDS, Shackleton et al. (2016) classified EDS based on their effects on the economy, physical and mental health, or aesthetic and cultural issues of human wellbeing.

Although EDS have been accounted in the scientific literature (Shapiro and Báldi, 2014), a comprehensive conceptual framework that incorporates both EDS and ES is lacking (compare Saunders and Luck, 2016; von Döhren and Haase, 2015). In our view, such a framework should address three conceptual issues: (1) nuisances from ecosystem to wellbeing can either be expressed as reduced ES (e.g. decrease of water provision, or reduction of soil erosion protection), or as genuine EDS (e.g., wildfires and pests; see Saunders and Luck, 2016; Shackleton et al., 2016 for reviews); (2) benefits and nuisances should account for human activities, since feedbacks between ecological changes and societal responses may trigger, enhance or reduce either ES or EDS; and, (3) an EDS framework should facilitate deliberation about both positive and detrimental aspects of ecosystems for human wellbeing acknowledging that there is not only one state in nature that can or should be maintained or restored through management. Some experts might consider that this likely opens a Pandora's Box (Shackleton et al., 2016). For example, conservationists who place an emphasis on native, wild nature may feel threatened by a concept and associated conceptual model that might be used to justify interventions in landscapes that they value for their lack of anthropogenic imprint (following Kronenberg, 2014; Villa et al., 2014). Yet clearly, explicit negotiations of management priorities might increasingly become unavoidable in coupled social-ecological landscapes. In such negotiations EDS recognition might contribute to better informed ecosystem management approaches and possibly optimised investments to increase both biodiversity and human wellbeing (Saunders and Luck, 2016; Shackleton et al., 2016; Stoll et al., 2015).

This paper proposes a general conceptual framework of EDS. The framework encompasses a detailed typology of different EDS, and it proposes a way to explicitly account for the role of social-ecological management in the valuation of ES and EDS. To this end, we highlight the importance of acknowledging the interconnected human-ecological nature of ecosystems. We propose to refine a precautionary approach to ecosystem management through a hierarchy: first identify potential ES and EDS, then protect ES and avoid or minimise EDS, restore and rehabilitate ES, and lastly mitigate and adapt to EDS. We illustrate our framework with plant invasions as a test case. Finally, we synthesise the wider usefulness of our typology and framework for the future study and management of benefits and nuisances arising from ecosystems. 


\section{Methods}

\subsection{The EDS typology}

To build the EDS typology, a literature search was performed in ISI Web of Science, between May and July 2015 (updated in February 2016). The search string was TOPIC $=\left("\right.$ ecosystem ${ }^{*}$ disservice ${ }^{* "}$ OR "environment* disservice*" OR "landscape disservice*" OR "ecologic*

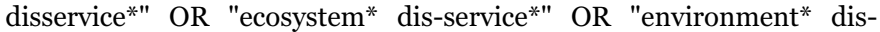
service $^{* "}$ OR "landscape dis-service ${ }^{* "}$ OR "ecologic ${ }^{*}$ dis-service*"). The time span of our search was 1900-2015. Following recommendations for increasing the reliability of literature reviews (Higgins and Green, 2011), our search was further extended to the first 50 records retrieved by a search on Google Scholar in February 2016. The records retrieved by ISI (number of records, $n=40$ ) and additional records retrieved from Google Scholar $(n=50)$ were scrutinised and nonrelevant records were discarded e.g. those which only mentioned the words "ecosystem disservice" but did not address their actual assessment or categorisation, or those which simply mentioned EDS, but focus on ES. We then reviewed the categories presented by each record from the final set of selected publications, and organised the examples and categories to produce a common EDS typology. Since our goal was not to conduct an exhaustive literature search on the EDS concept, the records indicated in this manuscript are purely illustrative of each EDS category.

We outline our proposed EDS categories in Section 3. They are grounded on the same premises that underlie ES, i.e. they influence different dimensions of human wellbeing (Agarwala et al., 2014; MA, 2005). Since the definition of human wellbeing is still being debated (Jax and Heink, 2015), here we consider human wellbeing as the desirable conditions for an individual or societal group (Jax and Heink, 2015), which depends on: objective attributes related to people's material and social contexts, subjective thoughts, feelings and satisfactions towards life, and psychological responses associated with social connectedness, security, and life satisfaction (Agarwala et al., 2014; Smith et al., 2013). Following Smith et al. (2013) we thus consider the following wellbeing dimensions: health, including life expectancy and mortality, and physical and mental health conditions; social cohesion, considering physical and emotional links that connect humans in society: education, resulting knowledge and skills; safety and security, as physical, personal and national freedom from harm and financial destabilisation; living standards, as the access to goods, services and resources; leisure time, as pleasurable activities away from work and responsibilities; spiritual and cultural fulfilment, as opportunities to fulfill spiritual and cultural needs; and connection to nature, as personal connectedness to ecosystems and biotas. These dimensions contribute to general life satisfaction and happiness (Smith et al., 2013).

\subsection{The ES and EDS framework and ES categories}

The integration of EDS into a general ES framework presented in Section 4 was grounded on the main ideas underlying the 'ecosystem service cascade model' (Haines-Young and Potschin, 2010). The ecosystem service cascade describes how the biophysical structure of ecosystems sustains the ecological functions and processes needed to provide ES. These ES then contribute to the benefits for human wellbeing with a respective value (see Haines-Young and Potschin, 2010; Spangenberg et al., 2014a for details).

Several initiatives have focused on the assessment or categorisation of ES. Prominent examples are the Millennium Ecosystem Assessment (MA, 2005), The Economics of Ecosystems and Biodiversity (TEEB, 2010), Mapping and Assessment of Ecosystems and their Services (MAES, 2013), the Common International Classification of Ecosystem Services (CICES; Haines-Young and Potschin, 2013), and the Intergovernmental Platform on Biodiversity and Ecosystem Services
(IPBES; Díaz et al., 2015). The ES categories adopted in our framework were based on CICES; these are considered applicable to different spatial and thematic scales, and are thus context-independent which allows for multi-study comparisons (Haines-Young and Potschin, 2013). CICES provides a five-level, hierarchical typology, the first level of which separates ES into provisioning, regulating and maintenance, and cultural services (Haines-Young and Potschin, 2013). A comparison of CICES, MA and TEEB classifications is presented in Table S1.

\subsection{The EDS typology and the ES-EDS framework illustrated with plant invasions}

A similar procedure to that used in Section 2.1 was considered to illustrate the EDS typology in line with an ES framework for (alien) plant invasions in Section 5. In this case, the search string was: TOPIC=("plant invader*" OR "exotic plant*" OR "alien plant"” OR "allochthonous plant" OR "plant invasion*" OR "tree invader" "exotic tree*" OR "alien tree*" OR "tree invasion*") AND ("ecosystem disservice $^{* "}$ OR "environment* disservice ${ }^{* "}$ OR "landscape disservice*" OR "ecologic* disservice ${ }^{* "}$ OR "ecosystem dis-service*" OR "environment $^{*}$ dis-service*" OR "landscape dis-service*" OR "ecologic* dis-

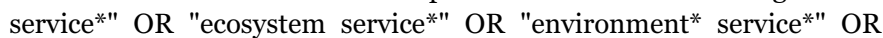
"landscape service*" OR "ecologic* service*"). The records retrieved in ISI $(n=184)$ were checked for relevance (e.g. excluding topics such as invaders from outer space). Each record was reviewed and we selected representative records to extract illustrative examples of the effects of plant invasions on human wellbeing.

\section{A typology for EDS}

Here we propose a detailed typology for EDS, considering a wide number of human wellbeing dimensions which can be negatively impacted by ecosystems in a direct way (Table 1). Our typology is based on an expanded definition of EDS that considers the direct "perceived or actual negative impacts on human wellbeing" (after Shackleton et al., 2016).

The typology includes five categories. The first category comprises health EDS and includes the direct consequences resulting from unwanted effects of biota on human health, including the outputs from their existence, e.g. air pollution caused by plant metabolism, viruses and pollen transmission. The second category comprises impacts on physical material for human life (material EDS), disrupting social cohesion, and living standards of human wellbeing. It includes those circumstances in which the physical expansion or introduction of living organisms results in outcomes that contribute directly to degradation of human materials and structures, such as buildings and houses, including traffic and communication infrastructure such as roads, e.g. through vegetation growth or animal excrements. The third category (security and safety EDS) considers impacts on the physical, personal and national security and safety of people. It includes all circumstances in which human freedom from harm becomes affected, either through, e.g. fear of animal attacks in wild or remote areas, fear of densely vegetated areas such as parks or forests due to a perceived higher risk of becoming a victim of a crime, or physical harm, e.g. caused by natural processes such as falling tree branches or fire, those that may be enhanced or mitigated through human activities. Cultural and aesthetic EDS (the fourth category) refer to biota or ecological outcomes that mostly impact on mental enjoyment of and connection with nature: human perception, aesthetics, spiritual, symbolic, cultural and religious values, such as species or landscapes considered as unpleasant. Leisure and recreation EDS, the fifth category, relate to ecosystem outputs that inhibit (the willingness for) physical connection with nature, through leisure and recreation activities, for instance by, e.g. vegetation occurrence obstructing water courses for water sports and other recreational activities in the wild.

The assumption that EDS have direct consequences for human 
Table 1

The proposed typology of ecosystem disservices (EDS) with examples from the literature.

\begin{tabular}{l} 
Ecosystem disservices (EDS) \\
\hline Health EDS - affecting human health \\
- Pollen release that provokes allergic reactions or intoxications; \\
- Animal bites (with or without poison) on humans; \\
- Zoonotic diseases transmitted to humans; \\
- Direct attacks by wild animals causing human injury or death; \\
- Plants that cause irritation when consumed by humans; \\
- Bacteria and virus that resist to human antibiotics; \\
- Methane emissions by plants breathed by humans; \\
- Toxins by algal blooms consumed by humans.
\end{tabular}

Material EDS - damaging built infrastructures

- Excrement from animals damaging buildings;

- Roots of plants damaging streets or pavements;

- Leaf litter considered a nuisance, e.g. stains resulting from leaf tannins;

- Natural disasters damaging infrastructures*.
Security and safety EDS - disrupting physical, personal, natio

- Fear and risk of getting lost in the wild due to lack of light, e.g. in dense forests;

- Fear and risk of attacks by wild animals (e.g. snakes, bears);

- Tree branches falling in roads and causing accidents or traffic delays;

- Dense vegetation provoking bad visibility in traffic and communication blockage;

- Fire-prone vegetation (e.g. dense biomass stands) in otherwise non-fire prone landscapes;

- Weather phenomena impacting human life (e.g. through loss of life);

- Wild animals within private facilities (lizards or poisonous spiders inside houses, or crocodile in backyards).

\section{Key references}

Baró et al., 2014; Bennett et al., 2010; Dobbs et al., 2014; Escobedo et al., 2011; Gómez-Baggethun and Barton, 2013; Limburg et al., 2010; Lyytimäki, 2014; Lyytimäki and Sipilä, 2009; Lyytimäki et al., 2008; Ma et al., 2015; Roy et al., 2012; Shackleton et al., 2016; Zhang et al., 2007.

Agbenyega et al., 2009; Dobbs et al., 2014; Escobedo et al., 2011; Gómez-Baggethun and Barton, 2013; Limburg et al., 2010; Lyytimäki and Sipilä, 2009; Lyytimäki et al., 2008; Roy et al., 2012; Sagie et al., 2013; Shackleton et al., 2016.

\section{al and financial stabilisation}

Agbenyega et al., 2009; Bennett et al., 2010; Escobedo et al., 2011; Escobedo et al., 2011; GómezBaggethun and Barton, 2013; Limburg et al., 2010; Lyytimäki, 2014; Lyytimäki and Sipilä, 2009; Lyytimäki et al., 2008; Ma et al., 2015; Roy et al., 2012; Shackleton et al., 2016; Zhang et al., 2007.

Cultural and aesthetic EDS - impacts on mental/ cultural interactions with nature

- Species perceived as disgusting and irritating by people;

- Species and landscapes considered unpleasant by people;

- Unpopular species due to religion, tradition or cultural legacies (e.g. snakes or goats associated with evil);

- Emergence of landscape new views by vegetation perceived as unpleasant.

Ango et al., 2014; Escobedo et al., 2011; Gómez-Baggethun and Barton, 2013; Lyytimäki, 2014; Lyytimäki and Sipilä, 2009; Lyytimäki et al., 2008; Roy et al., 2012; Shackleton et al., 2016.

Leisure and recreation EDS - causing inhibition of physical in

- Sounds and smells produced by animals disrupting physical connection with nature;

- Presence of weeds, pests or mosquitoes considered unpleasant for recreation;

- Blocking of sunlight by vegetation, creating too much shading for leisure activities;

- Algal blooms spoiling water courses for sport fishing or water sports;

- Habitats associated with the unknown, remoteness or wilderness considered unpleasant for outdoor activities;

- Preference for indoor activities due to unsuited surrounding landscapes.

\footnotetext{
" The incorporation of natural disasters and weather-related events as EDS is still under debate. We followed Shackleton et al. (2016: p. 592), considering that "hazard events or phenomena that have a link to biological process qualify to be EDS".
}

wellbeing allows us to distinguish EDS from situations in which an ecosystem nuisance is instead derived from the reduction of an ES (i.e. reduced ecosystem services). For instance, unwanted ecosystems functions can impact on well-recognised provisioning ES from agricultural (e.g. pests and weeds affecting crop growth; or fungus degrading processed food; Lyytimäki et al., 2008; Schäckermann et al., 2015), forest (e.g. timber quality damaged by fungus and other animal activities, or wood damaged by deer rub; Ango et al., 2014; Lyytimäki et al., 2008) or grazing systems (e.g. cattle diseases or poisoning by the consumption of toxic plants; Shackleton et al., 2016). Thus, the impact on people's living standards or the decrease of financial income that emerges from such impacts is determined by reduced ES, and not necessarily by genuine EDS (see Section 4 for details).

Additionally, our typology also overcomes the attribution of an $a$ priori normative judgement to ecosystem properties, e.g. since the same property can be considered in multiple EDS categories. Instead, the framework allows to account for how ecosystem functions, resulting from such properties, impact on wellbeing. For instance, the occurrence of snakes (as an ecosystem property) can bite (Health EDS), degrade infrastructures through excrements (Material EDS), give a sense of fear (Security and safety EDS), be considered as ugly (Cultural and aesthetic EDS), and occupy wild areas used for outdoor leisure (Leisure and recreation EDS). At the same time the occurrence of snakes can contribute to ES such as pest regulation, source of poison useful for medicinal purposes, and promote physical and intellectual experiences. This example shows the need for an integrative framing of both ES and EDS.

\section{Integrating EDS and ES into a general framework}

\subsection{The ES and EDS framework}

We propose a general framework that includes three main components of a social-ecological system to consider both ES and EDS: the ecological realm, the social realm, and the social-ecological interface 


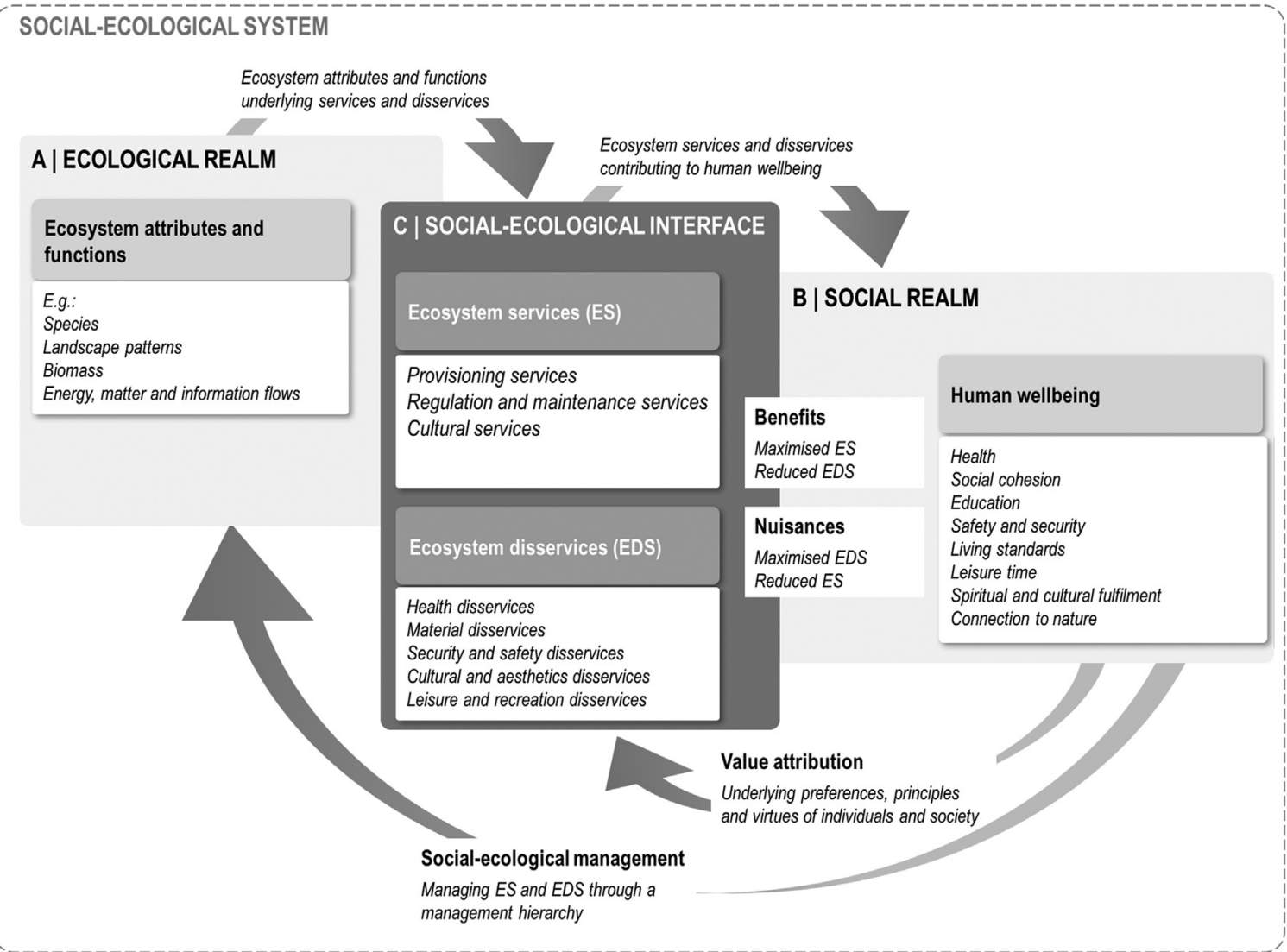

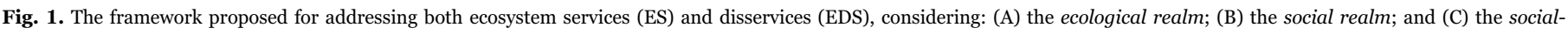
ecological interface. The framework assumes that the attribution of ES-EDS depends also on value attribution and social-ecological management.

(Fig. 1). Drawing into this model the flows underlying the ES cascade model (Haines-Young and Potschin, 2010; Spangenberg et al., 2014a), we argue that the provision of ES and EDS at the social-ecological interface depends on the attributes and functions generated in the ecological realm, while it contributes to benefits, i.e. increasing human wellbeing, or nuisances, i.e. reduction of human wellbeing in the social realm (Haines-Young and Potschin, 2013; Spangenberg et al., 2014a, 2014b).

The perception of benefits and nuisances in the social realm depends on the attribution of human values to the outputs of the ecological realm. However, in extending previous frameworks, we assume that the outputs from the ecological realm are also determined by social-ecological management actions that are interrelated with the valuation resulting from the social realm. To account for the dynamic role of humans in the interdependence of ecological and social processes we introduce the social-ecological interface where the attribution of ES and EDS happens in specific social-ecological, temporal and spatial contexts.

\subsection{The ecological realm}

The ecological realm (Fig. 1A) reflects the set of ecosystem attributes and functions that constitute or generate ES and EDS (Spangenberg et al., 2014a). It also considers the influence of abiotic components of the ecosystem such as weather events regulated by vegetation (Lyytimäki, 2014; Sagie et al., 2013) insofar as they are situated within the boundaries of an ecosystem (Shackleton et al., 2016). The ecosystem considered can be either a natural or anthropogenically influenced one, such as agricultural or forested land.

Ecosystem attributes and functions are neither positive nor negative: the same function or attribute can generate, maximise or reduce ES and EDS (cf. Saunders and Luck, 2016). For instance, the processes underlying a tree's carbon cycle can contribute to climate regulation through carbon sequestration (e.g. Baró et al., 2014), or produce volatile organic compounds, contributing to air pollution and human health problems (i.e. health EDS; e.g. Roy et al., 2012). This depends on the multi-spatial and temporal scales, and social contexts.

While the ecological realm can be anthropogenic in a material sense, it is 'value-free' in the sense that it describes the biophysical flows of energy, matter and information. These flows can change across spatial and temporal scales, and relate to the intensity and frequency of underlying ecosystem functions. It is, however, that by identifying those ecosystem attributes and functions that either enhance or reduce human wellbeing in given spatial and temporal contexts is conferred, depending on human-value attribution (Chan et al., 2012; Cumming et al., 2014; Reyers et al., 2013; Saunders and Luck, 2016). In our case, this human-value attribution can be understood as a measure of importance given to, or interest in, a particular phenomenon, be it ecological, economic or social.

\subsection{The social realm}

The social realm (Fig. 1B) relates to elements of human values, preferences, and principles (Chan et al., 2012), as well as human and institutional perception and behaviour produced in the complex, context-dependent dimensions of economics, politics, and culture. The latter define a demand for ES and an exposure to EDS, and the desirable or undesirable appropriation of the benefits or nuisances from ecosystems (Spangenberg et al., 2014b).

For example, landscape features can be perceived as cultural ES (as defined in CICES; Haines-Young and Potschin, 2013) by some people i.e. "the landscape is beautiful" - and as a cultural and aesthetic EDS (as proposed in Table 1) by other people - i.e. "the landscape is ugly". Such valuation thus depends on, among other things, the cognitive 
structure that people form through their experiences, individual cultures, preferences, principles, virtues, and norms, and the circumstances of the social, political and economic environment people are in (Brown and Westaway, 2011; Shackleton et al., 2016). Also, temporal advances in scientific, cultural, or generational knowledge might affect individual views of benefits or nuisances derived from the same ecosystem functions or attributes. For instance, environmental education can change the perception of particular species, e.g. bat species that were previously negatively perceived due to folklore (e.g. related to Dracula and feeding on human blood) become welcome after demystifying their negative impact and explaining their function in the ecosystem (e.g. pollinating tree fruits or predating mosquitoes; Kingston, 2015).

This operationalisation of the human valuation of ecosystem outcomes can be achieved through different approaches, ranging from monetary calculations of benefits or damages (TEEB, 2013), to the assessment of the willingness to do various things for a certain desire (Whelan et al., 2015), or the estimation of human happiness and satisfaction indices (Smith et al., 2013).

\subsection{The social-ecological interface}

The integration of the ecological and social realms at the socialecological interface (Fig. 1C) allows distinguishing ecosystem attributes and functions without having a-priori values, thereby opening the concept to a broader assessment of benefits and nuisances; a lack of which is one of the most recurring points of contention in ES research (cf. Schröter et al., 2014).

We assume that ES and EDS are not entirely antagonistic, yet their beneficial or detrimental effects can be opposite to each other, i.e. benefits can express ES or reduced EDS and nuisances can express EDS or reduced ES. For instance, human health can either benefit from several ES, such as food, pharmaceutics, and genetic materials; or from the mitigation of health EDS, namely the decrease of plant species with allergenic potential (reduced EDS). Contrastingly, human health can be impacted by the decrease in quality and quantity of such ES (reduced ES), as well as by the action of health EDS, namely food poisoning, ecosystem contamination, or diseases (Table 1). Also, human safety and security can be positively influenced by the capacity of ES to regulate and mitigate events such as floods and by the decrease in the occurrence of certain security and safety EDS, such as the removal of trees proned to falling. The opposite is also possible: human safety and security can be minimised either by the loss of regulation and maintenance ES, or by the enhancement of security and safety EDS (Table 2).

We emphasise that a clear separation of the social realm from the ecological realm is difficult since humans are part of both the ecological and social realm, with actions influencing the socialecological interface. Social-ecological management, particularly feedbacks between ecological shifts and societal responses to socialecological changes, may trigger, enhance or reduce either ES or EDS. For instance, placing societal assets (such as houses) or ecological features (such as alien species) in systems prone to disturbance such as floodplains affected by floods or storms, or in fire-prone vegetation, may enhance potential nuisances; and the promotion of monocultures or the suppression of natural processes may trigger EDS and reduce ES. Also, and especially under global change, ES and EDS depend on the human capacity to adapt to or learn from ecosystem changes, i.e. the social-ecological memory from Nykvist and von Heland (2014). This can, for instance, favour the provision of certain ES, e.g. since people learned how to cope with changes; or the disappearance of ES and emergence of EDS, e.g. since people did not adapt to the novel ecosystem (see Section 4.4).

\subsection{The management hierarchy for ES and EDS}

We argue that the notion of EDS should account for the role of management in the consideration of human values attributed to ecosystems. In the past, the precautionary approach has often guided ES management, i.e. the assumption that anthropogenic disturbances of (natural) ecosystems should be avoided or reverted if possible. Such a framework might be too narrow when considering EDS and the possibility of other ecosystems nuisances.

We expand a precautionary approach by suggesting a management hierarchy to guide social and technological actions. This hierarchy has been reported as being efficient in terms of policy development and management implementation for achieving ecosystem health and ecological sustainability (McKenney and Kiesecker, 2010; Tallis et al., 2015). We suggest to expand such framework so that it includes: first identify and evaluate potential ES and EDS, which are relevant for a given social-ecological system, then protect and maximise ES, avoid and minimise EDS while restore ES, and finally compensate and adapt to EDS (Tallis et al., 2015; Fig. 2).

Specifically, as a first step, the management hierarchy includes the identification and recognition of ecosystem outcomes, as well as the main trade-offs and dynamics between and within the distinct ES and EDS. This evaluation may be conducted through several approaches, such as ecological and economic methods (TEEB, 2013), or by assessments of human satisfaction, preference, or happiness (Smith et al., 2013). As a second step, the hierarchy includes the protection of ecosystems or the maximisation of benefits from natural resources, including the development of nature-based solutions (Kabisch et al., 2016). Avoidance and minimisation strategies include actions for preventing and reducing impacts, whether they are derived from EDS themselves or affect ES, e.g. by abstaining from detrimental management actions or pursuing technical solutions that allow for societal demands to be met while retaining ES supply. This can, for instance, be accomplished through technological development that minimises human dependency or overexploitation of ES, i.e. the non-ecosystem services proposed by Cumming et al. (2014). Offsets of human management can be included under the restoration and compensatory mitigation of nuisances (Tallis et al., 2015) e.g. by adopting social and technological mechanisms to actively restore the ecosystem in order to maximise desirable levels of ES provision, or to minimise the risk of exposure to a specific EDS (Biggs et al., 2012; Cumming et al., 2014; Reyers et al., 2013; Sagie et al., 2013). Adaptation considers strategies to cope with changes in the provision of ES (Biggs et al., 2012) and EDS, through actions that reduce such impacts without changing the likelihood that they will occur in the ecological realm, e.g. changes in people's behaviours and perceptions towards the nuisances associated to EDS in the social realm.

Considering humans as simultaneous occupants of both the social and ecological realm means that context-dependent actions for the implementation of this hierarchy in our framework can be accomplished both through interventions that target the social realm (e.g. public awareness, governance dialogue, and the creation of social norms, mechanisms and opportunities) and the ecological realm (e.g. remediation of impacted areas by means of appropriate technology, depending on the multi-scale, -temporal, and -actor context; Tallis et al., 2015). For instance, while we can anticipate (identify) the possibile occurrence of natural disasters, most often they can hardly be avoided. Yet, the protection and restoration of regulating ES and the minimisation and adaptation to the nuisances from natural disasters can be accomplished though appropriate risk management, e.g. reduction of vulnerabilities and enhancement of resilience at specific social, political, and economic dimensions (Biggs et al., 2012). Table 2 exemplifies social-ecological management actions that can influence the amount of benefits and nuisances from ES and EDS to human wellbeing. These social-ecological actions are nevertheless dependent on value-based considerations: negotiations, discussions, debates, 
Table 2

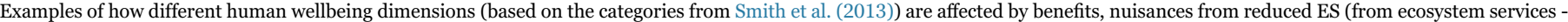
ES, based on CICES), ecosystem disservices (EDS, based on Table 1), and social-ecological management.

\begin{tabular}{l}
\hline Benefits to human wellbeing \\
\hline From ecosystem services (ES) \\
\hline Health \\
Provisioning ES - quality of food and \\
$\quad$ water, provision of pharmaceutics, \\
genetic materials; \\
Regulating and maintenance ES - quality \\
of water and food, regulation of \\
$\quad$ climate, air quality, floods; control of \\
pests and diseases. \\
Social cohesion \\
Cultural ES - physical and intellectual \\
interactions with ecosystems, \\
promoting a sense of place and shared \\
experiences between communities and \\
generations.
\end{tabular}

\section{Education}

Cultural ES - that allow intellectual development, cultural diversity, knowledge systems, educational values and cognitive richness through nature.

\section{Safety and security}

Provisioning ES - food and water security, energetic standards for safety.

Regulation and maintenance ES integrity and quality of ecosystems, and the mitigation of unwanted ('natural') phenomena.

\section{Living standards}

Provisioning, regulating and maintenance, and cultural ES that provide a real or perceived increase in quality for daily living, including food, ornamental, economic outcomes, and ecosystem well-functioning.

\section{Leisure time}

Regulating and maintenance ES pleasant environment increasing the willingness for people to enjoy nature.

Cultural ES - opportunities for physical outdoor activities.

\section{Spiritual and cultural fulfilment}

Cultural ES - physical, intellectual and spiritual interactions with nature, including aesthetic values, inspiration and cognitive development, and spiritual enrichment.

\section{Connection to nature}

Regulating and maintenance ES - sense of Inadequate maintenance of physical, fulfillment towards nature outputs.

Cultural ES - intellectual and physical interactions with nature.

Nuisances for human wellbeing

From reduced ecosystem services
Reduced mediation of waste, toxics and other nuisances (e.g. bio-chemical remediation by algae);

Inadequate maintenance of physical, chemical, biological conditions (incl. atmospheric composition and climate regulation, and chemical condition of waters).

Disrupted mediation of mass, water, and gaseous flows, incl. natural events that could not be mediated by biota and provoke material damages (namely storms and floods) in communication infrastructures that bring people together.

Disruption of maintenance of physical, chemical, biological conditions, namely unsuitable development of habitat nursery and animal reproduction.

Disrupted mediation of flows (e.g., flood and storm protection, or mass stabilisation and control of erosion rates).

Disrupted mediation of mass, water, and gaseous flows, incl. natural events that could not be mediated by biota and provoke material damages (namely storms and floods) in communication infrastructures.

Inadequate maintenance of physical, chemical, biological conditions (e.g. lack or disruption of pest and disease control);

Reduced mediation of waste, toxics and other nuisances (e.g. bio-chemical remediation by algae).

Disruption of development of habitat nursery and animal reproduction. chemical, biological conditions (e.g. lack or disruption of pest and disease control); Reduced mediation of waste, toxics and other nuisances (e.g. bio-chemical remediation by algae).
Health EDS - directly affecting human health, from pollution, poisoning and hygiene, to contamination, diseases and their spread (vectors such as mosquitos), and genetic resistance to pharmaceutics.

Social-ecological management

From ecosystem disservices (EDS)

Material EDS - biota damaging communication networks (namely rivers or roads) and lead to economic inequality

(economic damages to poorer communities).

Leisure and recreation EDS - unwanted ecosystem attributes that promote the lack of people connectedness.

Cultural and aesthetic EDS - repulsive feelings against species or ecosystem components and diminish the desire to learn with nature.

Security and safety EDS - EDS related to people's perception towards fear; physical exposure to ecosystems that threaten human safety or facilities or enhance costs associated to natural damages. Material EDS - degradation of infrastructures that leads to economic inequality (economic damages to poorer communities).

All types of EDS - considered intrusive in daily life, from health EDS, to cultural and aesthetic EDS conflicting with people's

beliefs, or material EDS promoting social costs.

Leisure and recreation EDS - disrupted physical participation of people with nature, including the opportunities for recreation and relaxation.

Cultural and aesthetic EDS - negative perception of nature on people's fulfillment, including cultural traditions, anxiety situations, fears, as well as unpleasant and repulsive due to beliefs (or past experiences).

Cultural and aesthetic EDS - responsible for negative perceptions about nature experiences

Leisure and recreation EDS - disrupting physical willingness to connect with nature.
Mechanisms and organisations that regulate individual and societal health. Adequate resource management and technology that promote better conditions and quality of ecosystems.

Social norms that drive perception and promote social cohesion and equitability.

Mechanisms that regulate the access to and enjoyment of ecosystems, creating opportunities for social interactions.

Education, finance and communication services.

Creation of opportunities to access natural areas for teaching, researching, and transferring knowledge into arts and culture.

Social mechanisms that provide protection, financial and social assistance in the case of damage. Integrated resource management and technology that regulate damages derived from wildlife or ecosystem processes.

Social mechanisms that promote wealth equality, improve living conditions, and that allow the maintenance and creation of green space e.g., cost regulation for human health and infrastructures.

Incentives for social interactions, networking and cohesion in nature (e.g., publicity).

Social opportunities to access and interact with nature, incl. activities that enhance the perceived quality of recreational and aesthetic areas (e.g., footpaths, gardens).

Social opportunities for regulating inequality and improving cultural, educational and spiritual inclusion in heritage.

Social mechanisms that protect and promote sacred and cultural aspects of ecosystems.

Policies and land use planning; community and faith-based initiatives.

Social regulation of the condition of ecosystems, promoting access to nature and biodiversity, recreation and aesthetics. 


\section{A | Identification / Evaluation}

B | Protection / Avoidance

C | Minimisation

D|Restoration

E | Compensation / Adaptation
Identification of potential ecosystem services and disservices relevant to the target socialecological context. Evaluation of trade-offs and dynamics between / within ecosystem services and disservices, e.g. through monetary approaches, satisfaction, or happiness towards life.

Protection of ecosystems with maximisation of ecosystem services, including the development of nature-based solutions. Avoidance of the effects of ecosystem disservices or of the undesirable minimisation of ecosystem services, by abstaining from detrimental management.

Minimising the impacts derived from ecosystem disservices or from the unwanted minimisation of ecosystem services, by adopting appropriate management systems that promote the reduction of the vulnerability to ecosystem disservices.

Restoration or rehabilitation of ecosystems, in order to maximise desirable levels of ecosystem services, or to minimise the risk of exposure to unwanted disservices, adopting social and technical mechanisms to actively manage ecosystem attributes and functions.

Adaptation to changes in the provision of services and disservices, through people's behaviours and perceptions towards the nuisances associated to such changes, without halting the likelihood that changes occur. Undesirable changes can be included under compensatory management.

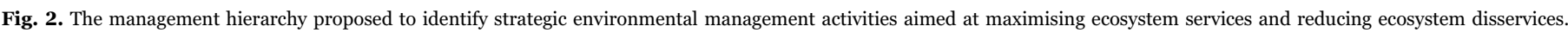

politics, and other values (and interests) involved in human choice towards evaluating and deciding which management activities are to be undertaken, e.g. to make priorities, or deal with conflicting views (Brown and Westaway, 2011; de Wit et al., 2001; McKenney and Kiesecker, 2010; Woodford et al., 2016).

\section{The ES and EDS typology and framework illustrated with plant invasions}

\subsection{Plant invasions from an EDS perspective}

Biological invasions are an interesting test case for our EDS typology and framework as negative outcomes on ecosystems and the need to manage ecosystems to minimise and adapt to such outcomes have long been discussed in the literature on the management of biological invasions (e.g. Brundu and Richardson, 2016; de Wit et al., 2001; Dickie et al., 2014; Funk et al., 2013). Here, we acknowledge alien plant species as those species that were introduced, accidentally or intentionally, by humans to new geographic areas. They may become invasive, i.e. spread from sites of introduction, and some become abundant and cause diverse impacts on the environment or society (Richardson et al., 2011). Many invasive plant species have major impacts on biodiversity and ecosystem functioning (Eviner et al., 2012; Fenesi et al., 2015; Simberloff et al., 2013).

Based on our proposed EDS typology, we can identify different EDS resulting from plant invasions: as providers of health EDS (e.g. through allergenic pollen transmission, Pyšek and Richardson, 2010; Schindler et al., 2015), security and safety EDS (e.g. creating fire occurrence in non-fire prone areas, Carruthers et al., 2011; Gaertner et al., 2014; Kull et al., 2011), cultural and aesthetic EDS (e.g. by forming monocultures perceived as unpleasant; Kueffer and Kull, 2017), or leisure and recreation EDS by spoiling rivers for water activities in the wild (Fig. 3a and b).

\subsection{Plant invasions at the social-ecological interface}

Although plant invasions can act as EDS providers (Shackleton et al., 2016), they can also provide important ES (Fig. 3c and d). Many alien plant species have been intentionally introduced to new areas to provide ES to individuals or groups of people, such as provisioning or aesthetics (Carruthers et al., 2011; Dickie et al., 2014; Kull et al., 2011), or to minimise the effects of a given EDS, such as pests (see also Fig. 3c,d). Many plant invaders are key resources in social-ecological systems around the world, especially in poor communities (Dickie et al., 2014; Kull et al., 2011), or in production systems (Koskela et al.,
2014; van Wilgen and Richardson, 2014).

At the ecological realm, plant invaders can impact on several attributes and functions (see Table S2) that sustain the provision of wood and food, while at the same time changing the functioning or quality of other ecosystem functions and attributes e.g. by reducing water quality and amount, or disrupting coastal sediment movement (Dickie et al., 2014; Gaertner et al., 2014; Koskela et al., 2014; van Wilgen and Richardson, 2014). The simple establishment of an invasive plant can contribute to both carbon sequestration and food provision in some spatial and temporal contexts (Dickie et al., 2014) or increase fire load and promote competition with native species in other contexts (de Wit et al., 2001; Fenesi et al., 2015). Also, changes in the biomass of invasive plants can contribute to ornamental enjoyment and spiritual perception (Carruthers et al., 2011; Shackleton et al., 2007) or result in the loss of a perceived wilderness character of landscapes and conservation areas (de Wit et al., 2001; Shackleton et al., 2007; see Table S2 for further examples).

The set of changes provoked by plant invasions are space and time dependent (Eviner et al., 2012): they are dependent on the stage of the invasion process (Simberloff et al., 2013). There is thus a complex interaction between the type and magnitude of invasion impacts depending on, among other things, the characteristics of the species, their invasive potential, the extent and time of invasion, and features of the invaded environment (Gaertner et al., 2014; Kueffer et al., 2013; Pyšek and Richardson, 2010; van Wilgen and Richardson, 2014). An example are ornamental plants that provide benefits in private gardens but cause nuisances once widespread in the wild (Dehnen-Schmutz et al., 2007).

The actual benefits (ES) or nuisances (EDS and reduced ES) emerging from the changes triggered by plant invasions in ecosystems can only be recognised in the social realm. Specifically, the variety of values, socio-political conditions, perceptions, attitudes, knowledge and ideas attributed to plant invaders by humans (Kueffer and Kull, 2017) define the level and direction of impacts from these species. One of the most emblematic examples can be recognised in the genus Acacia. In Madagascar, A. dealbata is exploited as a source of fuel wood and charcoal, and contributes substantially to living standards and social cohesion, especially in poorer villages. In contrast, in Portugal, where it was introduced for afforestation and soil erosion prevention (Kull et al., 2011), A. dealbata is a widespread invader which lowers biodiversity and increases fire hazard (Gaertner et al., 2014; Le Maitre et al., 2011). Another example is the mesquite (Prosopis spp.). The introduction of mesquite has been considered either as beneficial, due to the provision of food in Peru or wood in Kenya, or as source of security and safety EDS, leisure and recreation 


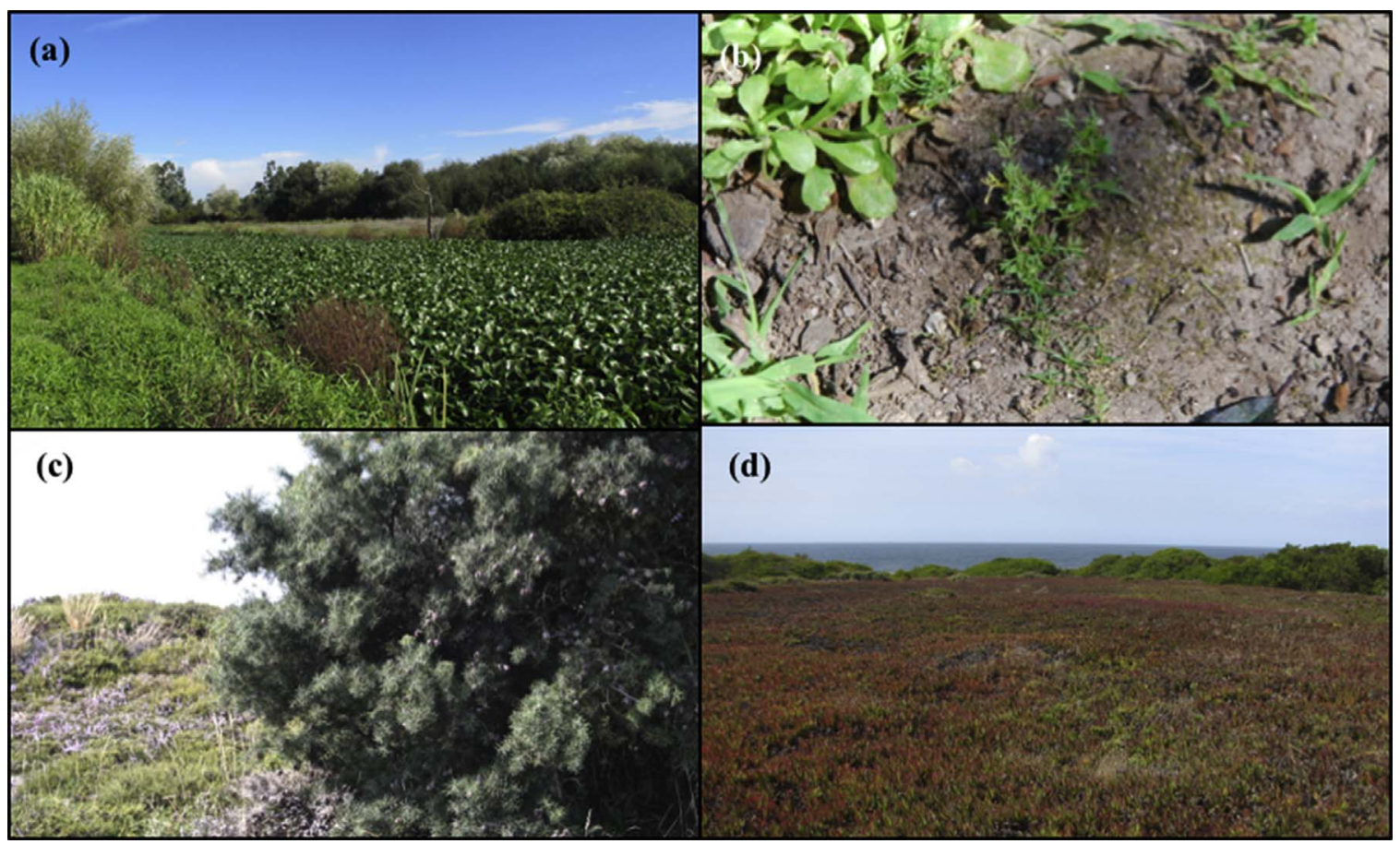

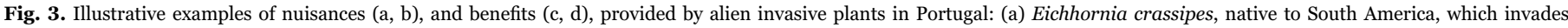

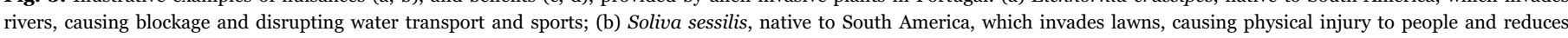

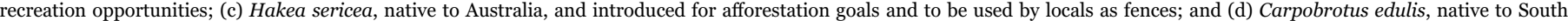
Africa, and introduced for ornamental uses and dune fixation in coastal habitats.

EDS and production EDS, such as physical injuries to humans in South Africa (Shackleton et al., 2015). Table 3 gives examples of benefits and nuisances promoted by plant invasions to human wellbeing.

As for the social realm, the beneficial or detrimental effects that plant invaders have on wellbeing inevitably shift according to the temporal and geographical context, and overall institutional, political and technological context of the human society impacted by plant invasions. For instance, while the introduction of Acacia mearnsii could be considered to have benefitted the South African economy in the past (Kull et al., 2011; van Wilgen and Richardson, 2014), the use of more advanced technology in the production of chemical tannins in South Africa reduced the current demand for the species (Carruthers et al., 2011). Another example results from the attribution of financial incentives, such as carbon credits (especially under the Kyoto protocol), which justifies afforestation with alien conifers in New Zealand (Dickie et al., 2014). Also, the perception of plant invasions as providers of benefits or nuisances can shift depending of the state of knowledge: although people may enjoy the beautiful flowers of Acacia dealbata or Carpobrotus edulis, the public awareness of these as promoters of water depletion and soil erosion in their lands, may alter people's perception of this species from beneficial to problematic (Marchante et al., 2010).

\subsection{Plant invasions and the management hierarchy}

A particular challenge of managing invasions is that their effects, valuation and management options are tightly interlinked (Humair et al., 2014; Kueffer, 2013; Woodford et al., 2016). Caution is warranted as an invasive plant may provide benefits or nuisances in the social realm, without necessarily being considered an a-priori beneficial or detrimental asset in the ecological realm. For instance, people will value invasions differently depending on available management options and the capacity to use ES and mitigate EDS provided by them, at certain geographical and temporal contexts (Kueffer, 2013).

There are thus trade-offs between beneficial and detrimental effects of invasions, and levels of acceptance of these differ between societal actors (Humair et al., 2014; Kueffer, 2013; Kueffer and Kull, 2017; Saunders and Luck, 2016; van Wilgen and Richardson, 2014). Consequently, managing ES and EDS resulting from invasions is often only possible at the social-ecological interface. At this interface, managing invasions (and further social-ecological challenges) could first rely on: (1) identifying specific situations - which ecosystem functions are being modified, at which level, and how irreversible these changes are; (2) considering ecosystem complexity - which potential ecological dynamics and feedbacks can be altered and in which direction of change; (3) realising opportunities in ecosystem service change - how to balance benefits versus nuisances, considering the distinct measures of human valuation; and (4) accounting for multiple social-ecological dimensions - how can invasion outcomes be altered in time, at multiple spatial scales, and through management, learning and changing social perception.

The management hierarchy that we propose (Section 4.4) offers a general strategy for assessing ES and EDS in the light of invasions, in that it provides an objective foundation on which to base decisions about maximising benefits and reducing nuisances for human wellbeing. These decisions should be considered based on human values and interests involved when deciding which management actions are to be implemented, e.g. through deliberation about conflicting views and priorities in invasion management (Bach and Larson, in press; de Wit et al., 2001; Humair et al., 2014). Management actions need to be tailored for particular geographic locations and time periods because the balance of ES and EDS will be different for different geographic and social-ecological contexts (Kueffer and Hirsch Hadorn, 2008).

We highlight four sequential strategies to manage the invasion process of alien plants from an ES-EDS perspective. The first strategy involves identification and assessment of potential changes in the ecological realm, including trade-off analyses that address the balance of benefits and nuisances provided by invasions in specific socialecological contexts. The second strategy involves mostly prevention and early-detection actions, through either the protection of preexisting ecosystem functions, or the enhancement of ecosystem functions and attributes leading to benefits, and the avoidance of potential 
Table 3

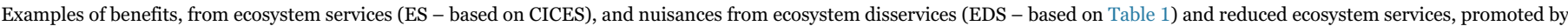
plant invasions on human wellbeing dimensions (categories based on Smith et al. (2013)).

Benefits from plant invasions to human wellbeing Nuisances from plant invasions for human wellbeing

\begin{tabular}{l} 
From ecosystem services (ES) \\
\hline Health \\
Provisioning ES: \\
Blood sugar medicine from Prosopis species in South \\
$\quad$ Africa (Shackleton et al., 2014);Several medicinal and \\
curative products derived from Eichhornia crassipes \\
in Bangladesh (Rana and Akhter, 2010);Styptics or \\
astringents extracted from Acacia mearnsii (Kull \\
et al., 2011; de Wit et al., 2001);Other products from \\
Acacia, Cinnamomum and Spathodea species across \\
the globe (Dickie et al., 2014).
\end{tabular}

the globe (Dickie et al., 2014).

\section{Social cohesion \\ Provisioning ES:}

Exchange of Opuntia ficus-indica fruits, supporting community relationships and nurturing reciprocity in South Africa (Shackleton et al., 2007).

Cultural ES:

Social equity associated to people's accessibility to Acacia species in South Africa, providing a sense of national symbolism (Carruthers et al., 2011);Poverty alleviation through employment, training and collaboration on managing Acacia species (Kull et al., 2011; McConnachie et al., 2013; Mugido et al., 2014; Shackleton et al., 2007).

\section{From reduced ecosystem services}

Reduction of the provision of medicinal products through the elimination of other medicinal plants, by Australian Acacia species in South Africa, Portugal and Chile (Le Maitre et al., 2011).

Removal of Acacia species in South Africa leads to social conflicts, decreasing social cohesion (Dickie et al., 2014).
Opportunities for environmental education and training focused on management of Acacia (Carruthers et al., 2011; Mugido et al., 2014) and Opuntia species (Shackleton et al., 2007).

\section{Safety and security}

Provisioning ES:

Financial security through cash income from Opuntia species in South Africa (Shackleton et al., 2007);Species as fence poles, namely Acacia and Pinus (Dickie et al., 2014).

Regulation and maintenance ES:

Soil conservation, stabilisation and fertility, land reclamation, windbreaks against sandstorm, watershed protection, dune stabilisation, roads protection, from Acacia and Pinus species in Kenya, Madagascar, South Africa, New Zealand (Carruthers et al., 2011; de Wit et al., 2001; Kull et al., 2011; Rana and Akhter, 2010; Richardson and van Wilgen, 2004; Shackleton et al., 2007, 2014).

\section{Living standards}

Provisioning ES:

Crops, fruits, honey, fuelwood, tannins, timber and pulp for paper, namely from Acacia spp., Eriobotrya japonica, Ficus carica, Opuntia spp., Morus alba and Psidium guajava (Carruthers et al., 2011; Dickie et al. 2014; Koskela et al., 2014; Kull et al., 2011; Le Maitre et al., 2011; Shackleton et al., 2007; van Wilgen and Richardson, 2014);Fodder for cattle from Opuntia species in South Africa (Shackleton et al., 2007).

Regulation and maintenance ES:

Carbon sequestration and nitrogen fixation (de Wit et al., 2001; Dickie et al., 2014; Kull et al., 2011; Qiu, 2015; van Wilgen and Richardson, 2014), namely by
Depletion of water sources for both consumption and irrigation, promoted by Acacia and Prosopis species in South Africa, Portugal and Madagascar (Carruthers et al., 2011; Funk et al., 2013; Kull et al., 2011; Le Maitre et al., 2011; Shackleton et al., 2015; van Wilgen and Richardson, 2014; Vicente et al., 2013);Disruption of soil-nutrient cycling, carbon and nitrogen fixation (Gaertner et al., 2014; Qiu, 2015); Loss of land for cattle due to dense vegetation (Kull et al., 2011; Shackleton et al. 2015; van Wilgen and Richardson,

2014);Destruction of timber resources by competition with other tree species (Richardson and van Wilgen, 2004);Pest transmission to tree plantations, promoted
Disruption of personal identity due to misleading national symbolism of Australian and African Acacia species (Carruthers et al., 2011).
Health EDS:

Physical injury due to Opuntia thorns in South Africa (Shackleton et al., 2007);Myocardia or gastroenteritis associated to the consumption of flowers and seeds of Ailanthus altissima and Robinia pseudoacacia, and cardiac problems and poisoning from Echium plantagineum and Rhododendron ponticum (Pyšek and Richardson, 2010);Pollen allergy and (or) dermatitis caused by A. altissima, Acacia dealbata, Ambrosia artemisiifolia, Cortaderia selloana, Heracleum mantegazzianum and Schinus terebinthifolius (Pyšek and Richardson, 2010);Transmission of human parasites through invasive plants (Schindler et al., 2015).

Cultural and aesthetic EDS:

Conflicts of interest between people (e.g. xenophobia, and conservationists versus land managers) due to Acacia and Jacaranda species in South Africa (Dickie et al., 2014;

van Wilgen and Richardson, 2014);Conflicts over limited natural resources between communities in Ethiopia and Kenya due to Prosopis species (Shackleton et al. 2014);Discrimination of people due to compromised selection of those benefiting from funding targeting invasive species management in South Africa (McConnachie et al., 2013). Material EDS:

Blocked accessibility between humans within nature reserves in South Africa caused by Opuntia ficus-indica (Shackleton et al., 2007);Disruption of 'healthy country' including important cultural sites in Aboriginal Australia (Bach and Larson, in press).

Compromised food security due to impacts on livestock health by Prosopis species in Kenya (Shackleton et al., 2014); Changes in fire and flood regimes promoted by Acacia species (Gaertner et al., 2014; Le Maitre et al., 2011; van Wilgen and Richardson, 2014);Modification of soil quality and promotion of soil erosion (de Wit et al., 2001; Funk et al., 2013; Shackleton et al., 2014).

Security and safety EDS

Harbouring of criminals in dense vegetation of Acacia mearnsii in South Africa (Shackleton et al., 2014);Species that promote fire hazard in non-fire prone areas (Carruthers et al., 2011; Gaertner et al., 2014; Kull et al., 2011; Richardson and van Wilgen, 2004).
Health EDS:

Constipation caused by the ingestion of Opuntia ficusindica fruits in South Africa (Shackleton et al., 2007).Material EDS:Blocked accessibility within lands due to Opuntia ficus-indica expansion (Shackleton et al., 2007).Security and safety EDS:Forests considered a security risk and used as latrine areas (Kull et al., 2011; Shackleton et al., 2007, 2014).Cultural and aesthetic EDS: 'Ugly' landscapes dominated by Acacia species (Carruthers et al., 2011).Leisure and recreation EDS:Physical injury through contact with the plant spines from several invasive species (Pyšek and Richardson, 2010; Shackleton et al., 2007, 2014). 
Table 3 (continued)

\begin{tabular}{|c|c|c|}
\hline \multirow{2}{*}{$\begin{array}{l}\text { Benefits from plant invasions to human wellbeing } \\
\text { From ecosystem services (ES) }\end{array}$} & \multicolumn{2}{|l|}{ Nuisances from plant invasions for human wellbeing } \\
\hline & From reduced ecosystem services & From ecosystem disservices (EDS) \\
\hline $\begin{array}{l}\text { Acacia species in Portugal (Vicente et al., } \\
\text { 2013);Sand stabilisation or erosion control, } \\
\text { especially in degraded areas by several tree species } \\
\text { (van Wilgen and Richardson, 2014). } \\
\text { Cultural ES: } \\
\text { Acacia species associated to heritage, religion, folklore, } \\
\text { fairy tales, legends and associated rituals (Kull et al., } \\
\text { 2011). }\end{array}$ & $\begin{array}{l}\text { by Acacia dealbata in Chile, A. longifolia in Portugal } \\
\text { and A. saligna in South Africa (Koskela et al., 2014; Le } \\
\text { Maitre et al., 2011);Other disease transmission to } \\
\text { livestock in Kenya (Shackleton et al., 2014). }\end{array}$ & \\
\hline \multicolumn{3}{|l|}{ Leisure time } \\
\hline $\begin{array}{l}\text { Cultural ES: } \\
\text { Species introduced as shade trees providing } \\
\text { opportunity for picnic grounds; e.g. pines in Cape } \\
\text { Town (e.g.Pooley, 2014), Eucalyptus species in South } \\
\text { Africa, Pinus species in New Zealand, and Rhammus } \\
\text { and Salix species in Australia (Dickie et al., 2014). }\end{array}$ & $\begin{array}{l}\text { Degradation of recreational areas and loss of touristic } \\
\text { experiences (de Wit et al., 2001; Le Maitre et al., 2011; } \\
\text { van Wilgen and Richardson, 2014);Blockage of water } \\
\text { bodies by Acacia mearnsii in South African rivers } \\
\text { (Shackleton et al., 2014), and tracks due to } \\
\text { impenetrable stands (Pyšek and Richardson, 2010). }\end{array}$ & $\begin{array}{l}\text { Leisure and recreation EDS: } \\
\text { Discomfort caused when barefooted people contact with } \\
\text { the thorns of Prosopis species (Shackleton et al., 2007). }\end{array}$ \\
\hline \multicolumn{3}{|l|}{ Spiritual and cultural fulfillment } \\
\hline $\begin{array}{l}\text { Cultural ES: } \\
\text { Encouraging native biodiversity conservation, due to } \\
\text { the appearance of exotic unpleasant Acacia species } \\
\text { (Carruthers et al., 2011);Spiritual and aesthetic values } \\
\text { attributed to "plant of my ancestors", production of } \\
\text { traditional wines and jams from Opuntia species in } \\
\text { South Africa (Shackleton et al., 2007);Use of Acacia } \\
\text { mearnsii for building traditional huts, sacred pool } \\
\text { protection, firewood to support traditional ceremonies, } \\
\text { rituals and celebrations in South Africa (Shackleton } \\
\text { et al., 2007);Visual amenity, ornamental purposes and } \\
\text { landscape re-green provided by invasive plants } \\
\text { (Carruthers et al., 2011; Dickie et al., 2014; Koskela } \\
\text { et al., 2014; Kull et al., 2011; Le Maitre et al., 2011; } \\
\text { Shackleton et al., 2007);Provision of a 'sense of place' } \\
\text { in urban areas associated to Jacaranda species in } \\
\text { South Africa and Pinus in New Zealand (Dickie et al., } \\
\text { 2014). }\end{array}$ & $\begin{array}{l}\text { Loss of sense of place and aesthetic values due to the } \\
\text { presence of invasive species, such as Acacia, Opuntia } \\
\text { and Prosopis species in South Africa and New Zealand } \\
\text { (de Wit et al., 2001; Le Maitre et al., 2011; Shackleton } \\
\text { et al., 2007);Threats to national pride by replacing } \\
\text { native, emblematic species (Carruthers et al., 2011; van } \\
\text { Wilgen and Richardson, 2014);Reduced cultural value } \\
\text { of sacred pools due to the presence of Acacia mearnsii } \\
\text { in South Africa (Shackleton et al., 2007). }\end{array}$ & $\begin{array}{l}\text { Cultural and aesthetic EDS: } \\
\text { Lack of beauty, art and fascination that humans } \\
\text { experience in wild nature or historic landscapes related to } \\
\text { the invasion by Acacia species (Carruthers et al., 2011). }\end{array}$ \\
\hline \multicolumn{3}{|l|}{ Connection to nature } \\
\hline $\begin{array}{l}\text { Regulation and maintenance ES: } \\
\text { Reduced harvesting pressure on native plants by the } \\
\text { collection of Acacia mearnsii (Carruthers et al., 2011; } \\
\text { Shackleton et al., 2007);Provision of food for native } \\
\text { wildlife, protection from predators, increased species } \\
\text { richness by invasive vegetation (Dickie et al., 2014; } \\
\text { Koskela et al., 2014). }\end{array}$ & $\begin{array}{l}\text { Genetic pollution, leading to the dilution and loss of } \\
\text { unique diversity in the wild, mainly by tree invasions } \\
\text { (Koskela et al., 2014; Le Maitre et al., 2011);Global } \\
\text { erosion of biodiversity and habitats (Carruthers et al., } \\
\text { 2011; Dickie et al., 2014; Kull et al., 2011; Le Maitre } \\
\text { et al., 2011; Shackleton et al., 2016; van Wilgen and } \\
\text { Richardson, 2014; Vicente et al., 2013). }\end{array}$ & $\begin{array}{l}\text { Cultural and aesthetic EDS: } \\
\text { Appearance of monospecific forests of Acacia cyclops, A. } \\
\text { longifolia, and A. saligna in South Africa (Gaertner et al., } \\
\text { 2014). }\end{array}$ \\
\hline
\end{tabular}

nuisances derived from alien/invasive plants (as EDS). The third strategy focuses on the mitigation and rapid response to both ES minimisation and EDS maximisation. This can be exemplified by distinct actions aiming at the treatment of the invader itself and its effects e.g. through eradication, containment and habitat restoration and rehabilitation (Funk et al., 2013; Simberloff et al., 2013; van Wilgen and Richardson, 2014). The last strategy involves adaptation to the occurrence or expansion of invasive plants, either by recognising potential novel ES (benefits), or accepting ES transformations (including reduced ecosystem services) and EDS emergence (nuisances). Examples from adaptation include the use of plant invaders for livelihoods, the harvesting of species for bioenergy goals and wood (Mugido et al., 2014), or their maintenance for carbon sequestration or landscape aesthetics (Dickie et al., 2014; Gaertner et al., 2016; Shackleton et al., 2007).

\section{Conclusions}

Ecosystem attributes and functions can contribute both positively and negatively to human wellbeing. We therefore clarify the role of ecosystem disservices (EDS) in the context of the ecosystem services (ES), in particular as the ES notion has become an additional argument for biodiversity conservation. We invite the adoption of a modified typology for integrating the terms of ES and EDS under a common framework that considers their relation to ecosystem functions, human wellbeing and feedbacks between human actions and ecosystem functioning at the social-ecological interface. We illustrate our suggestions with the case of plant invasions.

Our framework and application is underpinned by three important assumptions. The first is that the ensemble of attributes and functions in a given ecosystem (ecological realm) are intrinsically value-free. The benefits or nuisances derived from ES and EDS are, however, dependent on value attribution from individuals, groups of individuals and societies addressed by the social realm (Shapiro and Báldi, 2014). 
These are shaped by their specific economic, cultural, and political context. Second, the strong spatial, temporal and socio-economic context-dependency of ES and EDS may not allow for a universal typology and single delineation of ES and EDS. Differences in perceptions by societal actors and human management may trigger, maximise or minimise the impacts from ES and EDS. In this sense, ES and EDS are not necessarily antagonistic but complementary concepts, while their beneficial versus detrimental effects can be opposite to each other. Third, because of the influence of human actions, ES-EDS are coupled concepts and should not be perceived as static entities in dynamic ecosystems. In this context, a management hierarchy may be useful for achieving the overarching goal of sustainability, accounting for social and technological mechanisms to prevent, reduce or restore desirable levels of ES, and to minimise the risk of or exposure to a specific EDS. This human management perspective broadens the original focus of the ES-EDS notion. It elucidates the nature of beneficial flows from ecosystems to society and additionally accounts for the role of value attribution and ecosystem management in ES and EDS flows.

We are concerned that misinterpretations of our framework may arise. It may be argued that the proposed framework opens the door for too much negotiation about conservation and environmental management goals and priorities by explicitly considering a symmetry between ES and EDS. Our attempt to develop a comprehensive framework that is applicable across a wide range of ecosystems and socio-ecological contexts might also be criticised as being too reductionistic. Instead we believe that our framework facilitates more targeted dicussions and deliberations about dynamics related to nature and humans and how to manage ecosystems, thereby providing the means to steer debates beyond simplistic good versus bad dichotomies that currently bedevil many environmental management efforts (e.g. Gaertner et al., 2016; Woodford et al., 2016). In our view, it thus paves the way for improved ecosystem management that is tailored to particular social-ecological contexts. We do not suggest that less attention should be paid to the beneficial roles of ecosystems and biodiversity for human wellbeing. Rather, we hope that our approach widens the conceptual understanding of the valuing of ecosystem functioning, thereby expanding the repertoire of actions to protect and sustainably manage ecosystems and the services they provide. Finding ways to accurately balance ES and EDS with feasible valuations of costs and added values to humans is a major challenge. We call for more attention from scientists to broader social-ecological challenges. By advancing the thinking on EDS and by acknowledging the pivotal role of humans in the ES arena we hope that academics and practitioners will explicitly adopt a more dynamic notion of ES-EDS coupling in changing ecosystems to account for human action and management at the social-ecological interface.

\section{Acknowledgements}

Vaz was supported by FSE/MEC and FCT (Ph.D grant PD/BD/ 52600/2014); Vicente by POPH/FSE and FCT (Post-Doc grant SFRH/ BPD/84044/2012). This study was supported by the National SocioEnvironmental Synthesis Center (SESYNC; NSF DBI-1052875), the Helmholtz Centre for Environmental Research - UFZ and sDiv, the Synthesis Centre of the German Centre for Integrative Biodiversity Research (iDiv) Halle-Jena-Leipzig (DFG FZT 118). Richardson acknowledges support from the DST-NRF Centre of Excellence for Invasion Biology and the National Research Foundation of South Africa (grant 85417). We thank Cláudia Carvalho-Santos, for the motivating scientific discussions (CIBIO-InBIO); Thomson Reuters, for technical support during the literature search; João Gonçalves, Paulo Alves (University of Porto), Elizabete Marchante (University of Coimbra), and Lisia Lopes (University of Aveiro) for providing the images in Fig. 3.

\section{Appendix A. Supplementary material}

Supplementary data associated with this article can be found in the online version at http://dx.doi.org/10.1016/j.ecoser.2016.11.017.

\section{References}

Agarwala, M., Atkinson, G., Fry, B.P., Homewood, K., Mourato, S., Rowcliffe, J.M., Wallace, G., Milner-Gulland, E.J., 2014. Assessing the relationship between human well-being and ecosystem services: a review of frameworks. Conserv. Soc. 12 437-449.

Agbenyega, O., Burgess, P.J., Cook, M., Morris, J., 2009. Application of an ecosystem function framework to perceptions of community woodlands. Land Use Policy 26, $551-557$.

Ango, T.G., Börjeson, L., Senbeta, F., Hylander, K., 2014. Balancing ecosystem services and disservices: smallholder farmers' use and management of forest and trees in an agricultural landscape in southwestern Ethiopia. Ecol. Soc. 19, 30.

Bach, T.M., Larson, B.M.H., in press. Speaking about weeds: Indigenous elders' metaphors for invasive species and their management. Environmental Values. $\langle$ http://www.whpress.co.uk/EV/papers/Bach.pdf

Baró, F., Chaparro, L., Gómez-Baggethun, E., Langemeyer, J., Nowak, D.J., Terradas, J., 2014. Contribution of ecosystem services to air quality and climate change mitigation policies: the case of urban forests in Barcelona, Spain. AMBIO 43, 466-479.

Bennett, L.T., Mele, P.M., Annett, S., Kasel, S., 2010. Examining links between soil management, soil health, and public benefits in agricultural landscapes: an Australian perspective. Agric. Ecosyst. Environ. 139, 1-12.

Biggs, R., Schluter, M., Biggs, D., Bohensky, E.L., BurnSilver, S., Cundill, G., Dakos, V., Daw, T.M., Evans, L.S., Kotschy, K., Leitch, A.M., Meek, C., Quinlan, A., RaudseppHearne, C., Robards, M.D., Schoon, M.L., Schultz, L., West, P.C., 2012. Toward principles for enhancing the resilience of ecosystem services. Annu. Rev. Environ. Resour. 37, 421-448.

Bonn, A., Allott, T., Evans, M., Joosten, H., Stoneman, R., 2016. Peatland restoration and ecosystem services: science, policy and practice. In: Ecological Reviews, Cambridge University Press, Cambridge.

Brown, K., Westaway, E., 2011. Agency, capacity, and resilience to environmental change: lessons from human development, well-being, and disasters. Ann. Rev. Environ. Res. 36, 321-342.

Brundu, G., Richardson, D.M., 2016. Planted forests and invasive alien trees in Europe: a code for managing existing and future plantings to mitigate the risk of negative impacts from invasions. NeoBiota 30, 5-47.

Carruthers, J., Robin, L., Hattingh, J.P., Kull, C.A., Rangan, H., van Wilgen, B.W., 2011 A native at home and abroad: the history, politics, ethics and aesthetics of acacias, Divers. Distrib. 17, 810-821.

Chan, K.M.A., Satterfield, T., Goldstein, J., 2012. Rethinking ecosystem services to better address and navigate cultural values. Ecol. Econ. 74, 8-18.

Cumming, G.S., Buerkert, A., Hoffmann, E.M., Schlecht, E., von Cramon-Taubadel, S., Tscharntke, T., 2014. Implications of agricultural transitions and urbanization for ecosystem services. Nature 515, 50-57.

de Wit, M.P., Crookes, D.J., van Wilgen, B.W., 2001. Conflicts of interest in environmental management: estimating the costs and benefits of a tree invasion. Biol. Invasions 3, 167-178.

Dehnen-Schmutz, K., Touza, J., Perrings, C., Williamson, M., 2007. The horticultural trade and ornamental plant invasions in Britain. Conserv. Biol. 21, 224-231.

Dickie, I., Bennett, B., Burrows, L., Nuñez, M., Peltzer, D., Porté, A., Richardson, D.M., Rejmánek, M., Rundel, P., van Wilgen, B., 2014. Conflicting values: ecosystem services and invasive tree management. Biol. Invasions 16, 705-719.

Díaz, S., Demissew, S., Carabias, J., Joly, C., Lonsdale, C., Ash, N., Larigauderie, A. Adhikari, J.R., Arico, S., Báldi, et al., 2015. The IPBES Conceptual framework connecting nature and people. Curr. Opin. Environ. Sustain. 14, 1-16.

Dobbs, C., Kendal, D., Nitschke, C.R., 2014. Multiple ecosystem services and disservices of the urban forest establishing their connections with landscape structure and socio demographics. Ecol. Indic. 43, 44-55.

Escobedo, F.J., Kroeger, T., Wagner, J.E., 2011. Urban forests and pollution mitigation: analyzing ecosystem services and disservices. Environ. Pollut. 159, 2078-2087.

Eviner, V.T., Garbach, K., Baty, J.H., Hoskinson, S.A., 2012. Measuring the effects of invasive plants on ecosystem services: challenges and prospects. Invasive Plant Sci. Manag. 5, 125-136.

Fenesi, A., Vágási, C.I., Beldean, M., Földesi, R., Kolcsár, L.-P., Shapiro, J.T., Török, E., Kovács-Hostyánszki, A., 2015. Solidago canadensis impacts on native plant and pollinator communities in different-aged old fields. Basic Appl. Ecol. 16, 335-346.

Funk, J.L., Matzek, V., Bernhardt, M., Johnson, D., 2013. Broadening the case for invasive species management to include impacts on ecosystem services. BioScience 64, 58-63.

Gaertner, M., Larson, B.M.H., Irlich, U.M., Holmes, P.M., Stafford, L., van Wilgen, B.W., Richardson, D.M., 2016. Managing invasive species in cities: a framework from Cape Town, South Africa. Landsc. Urban Plan 151, 1-9.

Gaertner, M., Biggs, R., Te Beest, M., Hui, C., Molofsky, J., Richardson, D.M., 2014. Invasive plants as drivers of regime shifts: identifying high-priority invaders that alter feedback relationships. Divers. Distrib. 20, 733-744.

Gómez-Baggethun, E., Barton, D.N., 2013. Classifying and valuing ecosystem services for urban planning. Ecol. Econ. 86, 235-245.

Haines-Young, R., Potschin, M., 2010. The links between biodiversity, ecosystem services and human well-being. In: Raffaelli, D.G., Frid, C.L.J. (Eds.), Ecosystem Ecology: A New Synthesis. Cambridge University Press, UK, 110-139. 
Haines-Young, R., Potschin, M., 2013. Common international classification of ecosystem services (CICES): consultation on version 4, August-December 2012. EEA Framework contract No EEA/IEA/09/003.

Higgins, J.P., Green, S., 2011. Cochrane handbook for systematic reviews of interventions, version 5.1.0. 〈http://handbook.cochrane.org $\rangle$ (accessed 01.08.16).

Humair, F., Edwards, P.J., Siegrist, M., Kueffer, C., 2014. Understanding misunderstandings in invasion science: why experts don't agree on common concepts and risk assessments. Neobiota 20, 1-30.

Jax, K., Heink, U., 2015. Human well-being, In: Potschin, M., Jax, K. (Eds), OpenNESS Ecosystem Service Reference Book. EC FP7 Grant Agreement no. 308428. 〈http:// www.openness-project.eu/sites/default/files/SP HWB.pdf (accessed 15.07.16).

Kabisch, N., Frantzeskaki, N., Pauleit, S., Naumann, S., Davis, M., Artmann, M., Haase, D., Knapp, S., Korn, H., Stadler, J., Zaunberger, K., Bonn, A., 2016. Nature-based solutions to climate change mitigation and adaptation in urban areas: perspectives on indicators, knowledge gaps, barriers, and opportunities for action. Ecol. Soc. 21, 39.

Kingston, T., 2015. Cute, creepy, or crispy - how values, attitudes and norms shape human behavior toward bats. In: Voigt, C.C., Kingston, T. (Eds.), Bats of the Anthropocene. Springer International AG, 571-595.

Koskela, J., Vinceti, B., Dvorak, W., Bush, D., Dawson, I.K., Loo, J., Kjaer, E.D., Navarro, C., Padolina, C., Bordács, S., Jamnadass, R., Graudal, L., Ramamonjisoa, L., 2014. Utilization and transfer of forest genetic resources: a global review. For. Ecol. Manag. $333,22-34$.

Kronenberg, J., 2014. What can the current debate on ecosystem services learn from the past? Lessons from economic ornithology. Geoforum 55, 164-177.

Kueffer, C., Hirsch Hadorn, G., 2008. How to achieve effectiveness in problem-oriented landscape research - the example of research on biotic invasions. Liv. Rev. Landsc. Res., ., (2-2).

Kueffer, C., 2013. Integrating natural and social sciences for understanding and managing plant invasions. In: Larrue, S. (Ed.), Biodiversity and Societies in the Pacific Islands. Presses Universitaires de Provence, Collection "Confluent des Sciences" \& ANU ePress, Marseilles \& Canberra, 71-96.

Kueffer, C., Pysek, P., Richardson, D., 2013. Integrative invasion science: model organisms, multi-site studies, unbiased meta-analysis, and invasion syndromes. New Phytol. 200, 615-633.

Kueffer, C., Kull, C., 2017. Non-native species and the aesthetics of nature. In: Hulme, P., Vilà, M., Ruiz, G. (Eds.), Impact of Biological Invasions on Ecosystem Services. Springer, Berlin, (In press)http://www.springer.com/us/book/9783319451190.

Kull, C.A., Shackleton, C.M., Cunningham, P.J., Ducatillon, C., Dufour-Dror, J.-M., Esler, K.J., Friday, J.B., Gouveia, A.C., Griffin, A.R., Marchante, E., Midgley, S.J., Pauchard, A., Rangan, H., Richardson, D.M., Rinaudo, T., Tassin, J., Urgenson, L.S., von Maltitz, G.P., Zenni, R.D., Zylstra, M.J., 2011. Adoption, use and perception of Australian acacias around the world. Divers. Distrib. 17, 822-836.

Le Maitre, D.C., Gaertner, M., Marchante, E., Ens, E.-J., Holmes, P.M., Pauchard, A., O’Farrell, P.J., Rogers, A.M., Blanchard, R., Blignaut, J., Richardson, D.M., 2011. Impacts of invasive Australian acacias: implications for management and restoration. Divers. Distrib. 17, 1015-1029.

Limburg, K.E., Luzadis, V.A., Ramsey, M., Schulz, K.L., Mayer, C.M., 2010. The good, the bad, and the algae: perceiving ecosystem services and disservices generated by zebra and quagga mussels. J. Gt. Lakes Res. 36, 86-92.

Lyytimäki, J., 2014. Bad nature: newspaper representations of ecosystem disservices. Urban For. Urban Green. 13, 418-424.

Lyytimäki, J., Petersen, L.K., Normander, B., Bezák, P., 2008. Nature as a nuisance? Ecosystem services and disservices to urban lifestyle. Environ. Sci. 5, 161-172.

Lyytimäki, J., Sipilä, M., 2009. Hopping on one leg - the challenge of ecosystem disservices for urban green management. Urban For. Urban Green. 8, 309-315.

Ma, F., Eneji, A.E., Liu, J., 2015. Assessment of ecosystem services and dis-services of an agro-ecosystem based on extended energy framework: a case study of Luancheng County, North China. Ecol. Eng. 82, 241-251.

MA (Millennium Ecosystem Assessment), 2005. Ecosystems and Human Well-being: Synthesis. Island Press, Washington, DC.

MAES, 2013. Mapping and assessment of ecosystems and their services. An analytical framework for ecosystem assessments under Action 5 of the EU Biodiversity Strategy to 2020. Discussion paper. European Union.

Marchante, E., Marchante, H., Morais, M.C., Freitas, H., 2010. Combining methodologies to increase public awareness about invasive plants in Portugal. In: II International Workshop on Invasive Plants In Mediterranean Type Regions of The World, Conference paper. Trabzon, Turkey, 2-6 August.

McConnachie, M.M., Cowling, R.M., Shackleton, C.M., Knight, A.T., 2013. The challenges of alleviating poverty through ecological restoration: insights from South Africa's "working for water" program. Restor. Ecol. 21, 544-550.

McKenney, B.A., Kiesecker, J.M., 2010. Policy development for biodiversity offsets: a review of offset frameworks. Environ. Manag 45, 165-176.

Mugido, W., Blignaut, J., Joubert, M., De Wet, J., Knipe, A., Joubert, S., Cobbing, B., Jansen, J., Le Maitre, D., van der Vyfer, M., 2014. Determining the feasibility of harvesting invasive alien plant species for energy. S. Afr. J. Sci.. http://dx.doi.org/ $10.1590 /$ sajs.2014/20130397.

Nykvist, B., von Heland, J., 2014. Social-ecological memory as a source of general and specified resilience. Ecol. Soc. 19, 47.

Pooley, S., 2014. Burning Table Mountain: An environmental history of fire on the Cape Peninsula. Palgrave Macmillan, Basingstoke.

Price, C., 2014. Regulating and supporting services and disservices: customary approaches to valuation, and a few surprising case-study results. New Z. J. For. Sci. 44 (Suppl 1), S5.

Pyšek, P., Richardson, D.M., 2010. Invasive species, environmental change and management, and health. Annu. Rev. Environ. Resour. 35, 25-55.
Qiu, J., 2015. A global synthesis of the effects of biological invasions on greenhouse gas emissions. Glob. Ecol. Biogeogr. 24, 1351-1362.

Rana, M.P., Akhter, F., 2010. Uses of invasive alien plant species in Rema-Kalenga wildlife sanctuary of Bangladesh. J. Mt. Sci. 7, 380-385.

Rasmussen, L.V., Christensen, A.E., Danielsen, F., Dawson, N., Martin, A., Mertz, O., Sikor, T., Thongmanivong, S., Xaydongvanh, P., 2016. From food to pest: conversion factors determine switches between ecosystem services and disservices. Ambio. http://dx.doi.org/10.1007/s13280-016-0813-6.

Reyers, B., Biggs, R., Cumming, G.S., Elmqvist, T., Hejnowicz, A.P., Polasky, S., 2013. Getting the measure of ecosystem services: a social-ecological approach. Front. Ecol. Environ. 11, 268-273.

Richardson, D.M., Pyšek, P., Carlton, J.T., 2011. A compendium of essential concepts and terminology in invasion ecology. In: Richardson, D.M. (Ed.), Fifty years of invasion ecology. The legacy of Charles Elton. Wiley-Blackwell, 409-420.

Richardson, D.M., van Wilgen, B.W., 2004. Invasive alien plants in South Africa: how well do we understand the ecological impacts? South Afr. J. Sci. 100, 45-52.

Roy, S., Byrne, J., Pickering, C., 2012. A systematic quantitative review of urban tree benefits, costs, and assessment methods across cities in different climatic zones. Urban For. Urban Green. 11, 351-363.

Sagie, H., Morris, A., Rofè, Y., Orenstein, D.E., Groner, E., 2013. Cross-cultural perceptions of ecosystem services: a social inquiry on both sides of the IsraeliJordanian border of the Southern Arava valley desert. J. Arid Environ. 97, 38-48.

Saunders, M.E., Luck, G.W., 2016. Limitations of the ecosystem services versus disservices dichotomy. Cons. Biol.. http://dx.doi.org/10.1111/cobi.12740.

Schäckermann, J., Mandelik, Y., Weiss, N., von Wehrden, H., Klein, A.-M., 2015. Natural habitat does not mediate vertebrate seed predation as an ecosystem dis-service to agriculture. J. Appl. Ecol. 52, 291-299.

Schindler, S., Staska, B., Adam, M., Rabitsch, W., Essl, F., 2015. Alien species and public health impacts in Europe: a literature review. NeoBiota 27, 1-23.

Schröter, M., van der Zanden, E.H., van Oudenhoven, A.P.E., Remme, R.P., SernaChavez, H.M., de Groot, R.S., Opdam, P., 2014. Ecosystem services as a contested concept: a synthesis of critique and counter-arguments. Cons. Lett. 6, 514-523.

Shackleton, C.M., Ruwanza, S., Sinasson Sanni, G.K., Bennett, S., Lacy, P., Modipa, R., Mtati, N., Sachikonye, M., Thondhlana, G., 2016. Unpacking Pandora's Box: understanding and categorising ecosystem disservices for environmental management and human wellbeing. Ecosystem 19, 587-600.

Shackleton, R.T., Le Maitre, D.C., Pasiecznik, N.M., Richardson, D.M., 2014. Prosopis: a global assessment of the biogeography, benefits, impacts and management of one of the world's worst woody invasive plant taxa. AoB Plants. http://dx.doi.org/10.1093/ aobpla/plu027.

Shackleton, R.T., Le Maitre, D.C., van Wilgen, B.W., Richardson, D.M., 2015. Use of nontimber forest products from invasive alien Prosopis species (mesquite) and native trees in South Africa: implications for management. For. Ecosyst. 2, 16. http:// dx.doi.org/10.1186/s40663-015-0040-9.

Shackleton, C.M., McGarry, D., Fourie, S., Gambiza, J., Shackleton, S.E., Fabricius, C., 2007. Assessing the effects of invasive alien species on rural livelihoods: case examples and a framework from South Africa. Hum. Ecol. 35, 113-127.

Shapiro, J., Báldi, A., 2014. Accurate accounting: how to balance ecosystem services and disservices. Ecosyst. Serv. 7, 201-202.

Simberloff, D., Martin, J.-L., Genovesi, P., Maris, V., Wardle, D.A., Aronson, J., Courchamp, F., Galil, B., García-Berthou, E., Pascal, M., Pyšek, P., Sousa, R., Tabacchi, E., Vilà, M., 2013. Impacts of biological invasions: what's what and the way forward? Trends Ecol. Evol. 28, 58-66.

Smith, L.M., Case, J.L., Smith, H.M., Harwell, L.C., Summers, J.K., 2013. Relating ecosystem services to domains of human well-being: foundation for a U.S. index. Ecol. Indic. 28, 79-90.

Spangenberg, J.H., von Haaren, C., Settele, J., 2014a. The ecosystem service cascade: further developing the metaphor. Integrating societal processes to accommodate social processes and planning, and the case of bioenergy. Ecol. Econ. 104, 22-32.

Spangenberg, J.H., Görg, C., Truong, D.T., Tekken, V., Bustamante, J.V., Settele, J., 2014b. Provision of ecosystem services is determined by human agency, not ecosystem functions. Four case studies. Int. J. Biodiv. Sci. Ecosyst. Serv. Manag. 10, $40-53$.

Stoll, S., Frenzel, M., Burkhard, B., Adamescu, M., Augustaitis, A., Baeßler, C., Bonet, F.J., Carranza, M.L., Cazacu, C., Cosor, G.L., Díaz-Delgado, R., Grandin, U., Haase, P., Hämäläinen, H., Loke, R., Müller, J., Stanisci, A., Staszewski, T., Müller, F., 2015. Assessment of ecosystem integrity and service gradients across Europe using the LTER Europe network. Ecol. Model. 295, 75-87.

Swinton, S.M., Lupi, F., Robertson, G.P., Hamilton, S.K., 2007. Ecosystem services and agriculture: cultivating agricultural ecosystems for diverse benefits. Ecol. Econ. 64, $245-252$.

Tallis, H., Kennedy, C.M., Ruckelshaus, M., Goldstein, J., Kiesecker, J.M., 2015. Mitigation for one and all: an integrated framework for mitigation of development impacts on biodiversity and ecosystem services. Environ. Impact Assess. Rev. 55, 21-34.

Tassin, J., Kull, C.A., 2015. Facing the broader dimensions of biological invasions. Land Use Policy 42, 165-169.

TEEB - The Economics of Ecosystems and Biodiversity, 2013. Guidance Manual for TEEB Country Studies. Version 1.0.

van Wilgen, B.W., Richardson, D.M., 2014. Challenges and trade-offs in the management of invasive alien trees. Biol. Invasions 16, 721-734.

Vicente, J.R., Pinto, A.T., Araújo, M.B., Verburg, P.H., Lomba, A., Randin, C.F., Guisan, A., Honrado, J.P., 2013. Using life strategies to explore the vulnerability of ecosystem services to invasion by alien plants. Ecosystems 16, 678-693.

Villa, F., Bagstad, K.J., Voigt, B., Johnson, G.W., Athanasiadis, I.N., Balbi, S., 2014. The misconception of ecosystem disservices: how a catchy term may yield the wrong 
messages for science and society. Ecosyst. Serv. 10, 52-53.

von Döhren, P., Haase, D., 2015. Ecosystem disservices research: a review of the state of the art with a focus on cities. Ecol. Indic. 52, 490-497.

Whelan, C.J., Şekercioğlu, C.H., Wenny, D.G., 2015. Why birds matter: from economic ornithology to ecosystem services. J. Ornithol. 156 (Supplement 1), 227-238.
Woodford, D.J., Richardson, D.M., MacIsaac, H.J., Mandrak, N.E., van Wilgen, B.W., Wilson, J.R.U., Weyl, O.L.F., 2016. Confronting the wicked problem of managing biological invasions. NeoBiota 31, 63-86.

Zhang, W., Ricketts, T.H., Kremen, C., Carney, K., Swinton, S.M., 2007. Ecosystem services and dis-services to agriculture. Ecol. Econ. 64, 253-260. 